\title{
Rhinosinusitis in Secondary School Children-Part 1: Pilot study of the MSNOT-20 Young Person Questionnaire $(M S Y P Q)^{*}$
}

Amtul S. Sami and Glenis K. Scadding

ENT and Allergy Department, Royal National Throat, Nose and Ear Hospital, London, United Kingdom
Rhinology 52: 215-224, 2014 DOI:10.4193/Rhino12.011-2

*Received for publication: January 16,2012

Accepted: December 28, 2013

\begin{abstract}
Background: The SNOT-20 questionnaire, a valid disease related quality of life instrument for rhinosinusitis, was modified for use in secondary school children and became the Modified Sino Nasal Outcome Test -20 Young Person Questionnaire, MSYPQ.
\end{abstract}

Methododology: MSYPQ was evaluated in a pilot study of disease (rhinosinusitis) and non-disease according to criteria in the European Position Paper on Rhinosinusitis and Nasal polyposis (EPOS).

Results: Those children who were suffering from rhinosinusitis according to the EPOS criteria showed significantly high scores on MSYPQ, whereas those who did not have rhinosinusitis had very low to zero scores on the MSYPQ.

Conclusion: This pilot study confirmed that the MSYPQ recognises rhinosinusitis symptoms in the 11-16 year age group with its effect on quality of life and is a suitable instrument to investigate the prevalence and impact of this problem in young people.

Key words: rhinitis, sinusitis, prevalence, EPOS, secondary school

\section{Introduction}

Rhinitis means inflammation of the nasal mucous membrane and often precedes sinusitis (inflammation of the lining of the paranasal sinuses), it is rare for sinusitis to occur without coexisting rhinitis and as such the most appropriate term for both is rhinosinusitis ${ }^{(1,2)}$. Rhinitis and rhinosinusitis are some of the most frequent diseases in the population ${ }^{(1,3)}$. Rhinosinusitis is particularly prevalent in childhood where MRI scans reveal sinus abnormalities in $45 \%$ of children aged 4 to 8 years ${ }^{(4)}$, probably due to frequent upper respiratory tract infections. There appears to be a decrease in rhinosinusitis prevalence around the age of 7 to 9 years, similar to that seen in otitis media with effusion ${ }^{(5-7)}$.

A health care expenditure study in the USA found that children were responsible for $30.6 \%$ of the overall spending from government funding for their respiratory problems including sinusitis, otitis media, asthma and upper respiratory tract infections ${ }^{(8)}$.

In the age group of 11 to 16 year olds rhinitis is not only important as a disease entity affecting social life and causing limitations of activity, it also affects the performance at school, in examinations and is responsible for reduced productivity and concentration in school ${ }^{(9-11)}$. The International Study of Asthma and Allergy in Childhood (ISAAC) has reported extensively on rhinitis in teenagers aged 13 to $14^{(12)}$. However, there is little data on prevalence of rhinitis or rhinosinusitis in older children. The question is of importance since rhinosinusitis has marked effects on quality of life and is likely to be a factor in poor educational attainment $(9,10,13,14)$.

Having used, with permission from the author Jay Piccirillo,

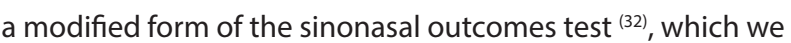


termed MSNOT-20, in an adult community survey ${ }^{(24)}$ we decided to adapt this further for use in teenage schoolchildren.

The design of the questionnaire and the choice of the scoring system were aided by experience gained from other questionnaires ${ }^{(25-33)}$. The advantages of the SNOT-20 questionnaire are that items were derived from a valid measure ${ }^{(26,32,33)}$. Secondly, the SNOT-20 includes a wide range of items that are important to patients with rhinitis and rhinosinusitis. Thirdly the SNOT-20 allows patients to identify which items are most important to them, independent of the magnitude of the problem: this helps the physician to focus treatment and is vital to the appreciation of the impact of the disease on quality of life, for both research and clinical purposes.

Additionally, the SNOT-20 has been shown to be sensitive to change in symptoms ${ }^{(25,26)}$ and can be combined with other outcome measures to assess consistency, reliability and care costs, to provide a more complete description of the outcome ${ }^{(25,33)}$.

The MSNOT-20 questionnaire was modified, according to the requirements of the age group being assessed and the suggestions of the ethical committee, to make it appropriate to use in an interview-based and postal survey in children. These modifications created the Modified SNOT-20 for Young Persons questionnaire (MSYPQ).

With regards to symptom detection: the MSYPQ asks about symptoms in the last two weeks in addition to long lasting and persistent symptoms. This allows the questionnaire to detect transient and short-lived symptoms, such as those related to acute as well as chronic rhinosinusitis. As such, this questionnaire is aimed at nasal and sinus disease with or without nasal polyps. Since seasonal influences may alter the response at different times of the year this survey was undertaken outside the hay fever season.

The MSYPQ was initially explored in a small pilot project comparing its findings to the standard European criteria for the diagnosis of rhinosinusitis provided by the European Position Paper on Rhinosinusitis and Nasal Polyps ${ }^{(34)}$.

\section{Materials and methods}

\section{Ethical considerations}

Ethical approval for the study was obtained from the East London ethical committee; the ethical approval number allocated is 06/q0605/57.

\section{Questionaire}

The SNOT-20 questionnaire is a disease specific questionnaire and was modified in order to make it a disease specific and qua- lity of life questionnaire for rhinosinusitis in the target group. This was done by adding sections 1 and 3 with a modification made to the disease specific section 2 .

Section 1 consists of demographic details, ethnicity and family history Section 2 was modified by adding a question regarding 'nasal blockage' instead of 'sad'. Although 'sad' is significant in the patient experience it is not disease-specific hence inappropriate in the disease-specific section of the questionnaire, this led to its exclusion. 'Nasal blockage' replaced 'sad' to ensure that this major and diagnostic symptom of nasal and sinus disease was detected and its severity documented.

Section 3 was added to accommodate a quality of life and socioeconomic analysis. Quality of life connotes the vitality and concept of general health in the subject and this section is included to determine this. This is done by identifying the level of impairment to patients' daily functioning as a result of their disease and the efficacy of any treatment received. This section consists of questions regarding duration of disease, treatment used, type of treatment, surgical intervention, perceived efficacy of treatment, financial burden on the individual, number of visits to the family doctor and number of days taken off work.

Sections 1, 2, 3 were combined and became Modified SNOT-20 (MSNOT-20). This questionnaire was used in a large scale adult survey in the area of Farnborough ${ }^{(24)}$. To make the MSNOT-20 questionnaire appropriate for our study, which looked at children in secondary school in the 11 to 16 age group (also known as adolescents), further changes were made in the 'demographic' section (section 1) and the 'quality of life' section (section 3) of the questionnaire with recommendations from the ethical committee. Modifications carried out in the 'demographic' section included omission of 'name', replaced with a unique ID number, individual students 'address' was replaced with 'school address and the section on 'housing' was limited.

This questionnaire was termed the modified SNOT-20 young persons questionnaire (MSYPQ, see Appendix). Before employing it on a large scale a pilot study was undertaken to see if it could distinguish normal subjects from those with rhinitis/ rhinosinusitis.

\section{Pilot project}

This was carried out in one school with the permission of the head teacher, parents/guardian and consent of each young person. Twenty subjects were chosen: ten volunteers with physician-diagnosed rhinosinusitis (the disease group), which was confirmed by the research doctor before enrolling them onto the research project on the basis of the EPOS epidemiology-based diagnostic criteria for rhinosinusitis (these are the diagnostic 


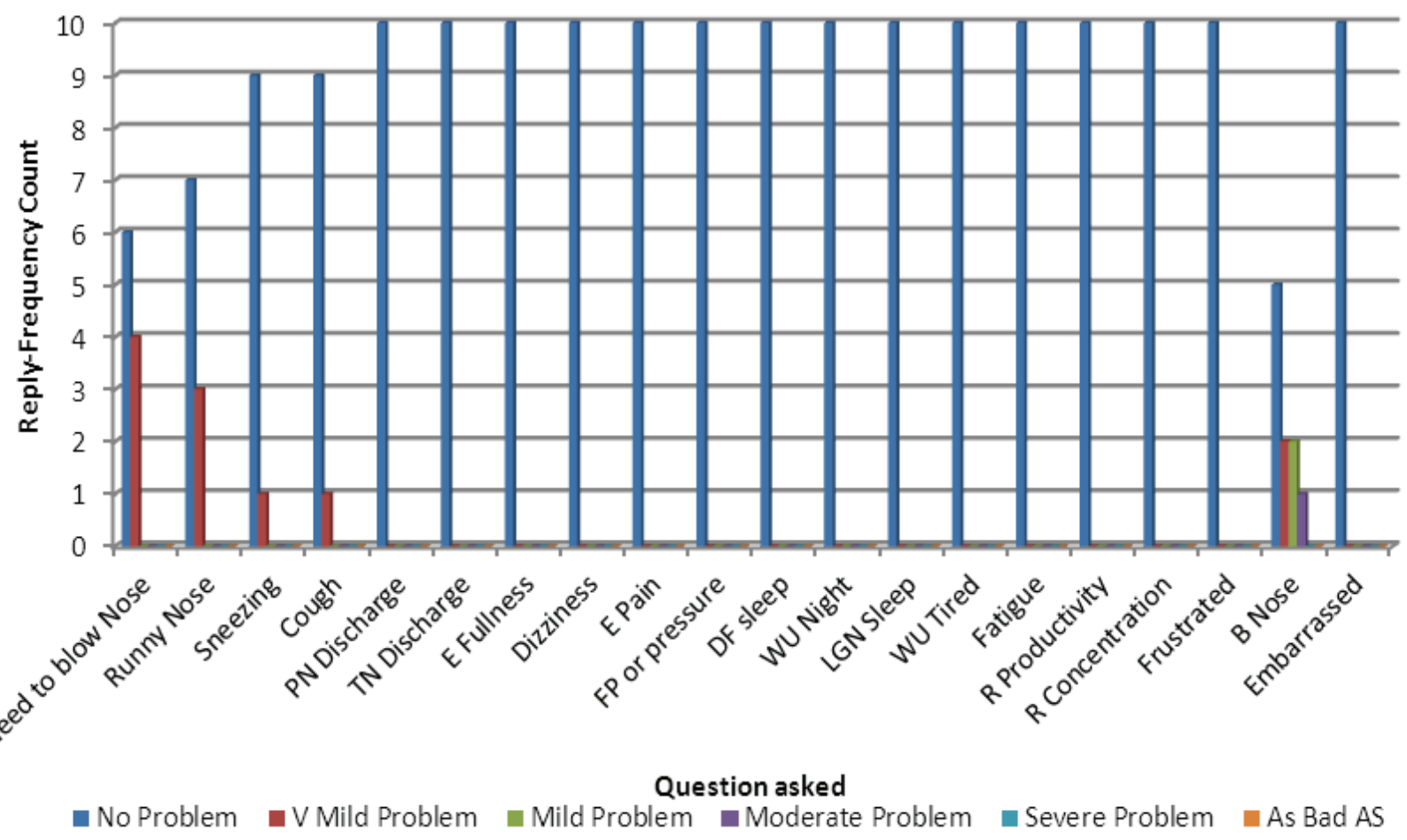

Figure 1. Graphical representation of healthy group $(n=10)$. This figure represents the lack of symptoms, indicated by "no problem" reporting, by the healthy group, with only a few subjects reporting "very mild" or "mild" symptoms.

guidelines used for epidemiological studies in the absence of radiographic or endoscopic evidence for disease diagnosis from EPOS $2007^{(2)}$ i.e. the presence of two symptoms: one to be either nasal congestion/obstruction/blockage or facial pain/pressure, together with either the other or with or discoloured discharge or a reduced sense of smell). The other ten volunteers lacked these criteria and considered themselves to be healthy.

These selected individuals completed the MSYPQ in a face to face interview with the research doctor. The data was then extracted from the questionnaires and statistically analysed to identify two key issues:

1. The differentiation power of the MSYPQ

2. The reliability of the MYSPQ

\section{Results}

\section{Group Analysis}

By comparing the disease (EPOS+) to healthy (EPOS-) group, the differentiation capacity of the MSYPQ was identified.

There are twenty questions in the disease specific section of MSYPQ (see Appendix). Each is answered according to a Likert scale of 0-5, where zero is graded as 'no problem' and five is graded as, 'as bad as it can be'.
Healthy subject data is shown in Figure 1 where to fifteen of the twenty questions all subjects responded with zero, 'no problem'. A small number of healthy subjects showed very mild and mild symptoms such as the need to blow the nose and blocked nose.

Figure 2 shows the disease group responses to the MYSPQ questions. Comparing the two figures there is significant variation between the diseased and the healthy group in their response for most questions, except for the question regarding nasal obstruction (question 19), waking up at night (question 12) and difficulty falling asleep (question 11). The overlap in questions 11 and 12 occurred because some rhinitis/rhinosinusitis subjects responded no problem and in question 19 the problem also existed in some healthy subjects.

The overall mean and standard deviation was $0.09 \pm 0.1366$ for the healthy subjects and $1.675 \pm 1.185$ for the disease group. The disease group mean was significantly greater than the healthy mean plus over 3 standard deviations. This shows that the responses of the questionnaire can be used as a differentiation tool of disease to non-disease.

Comparison of individual response to each question from both disease and healthy group showed the response for each question is lower in the healthy group when compared to those 

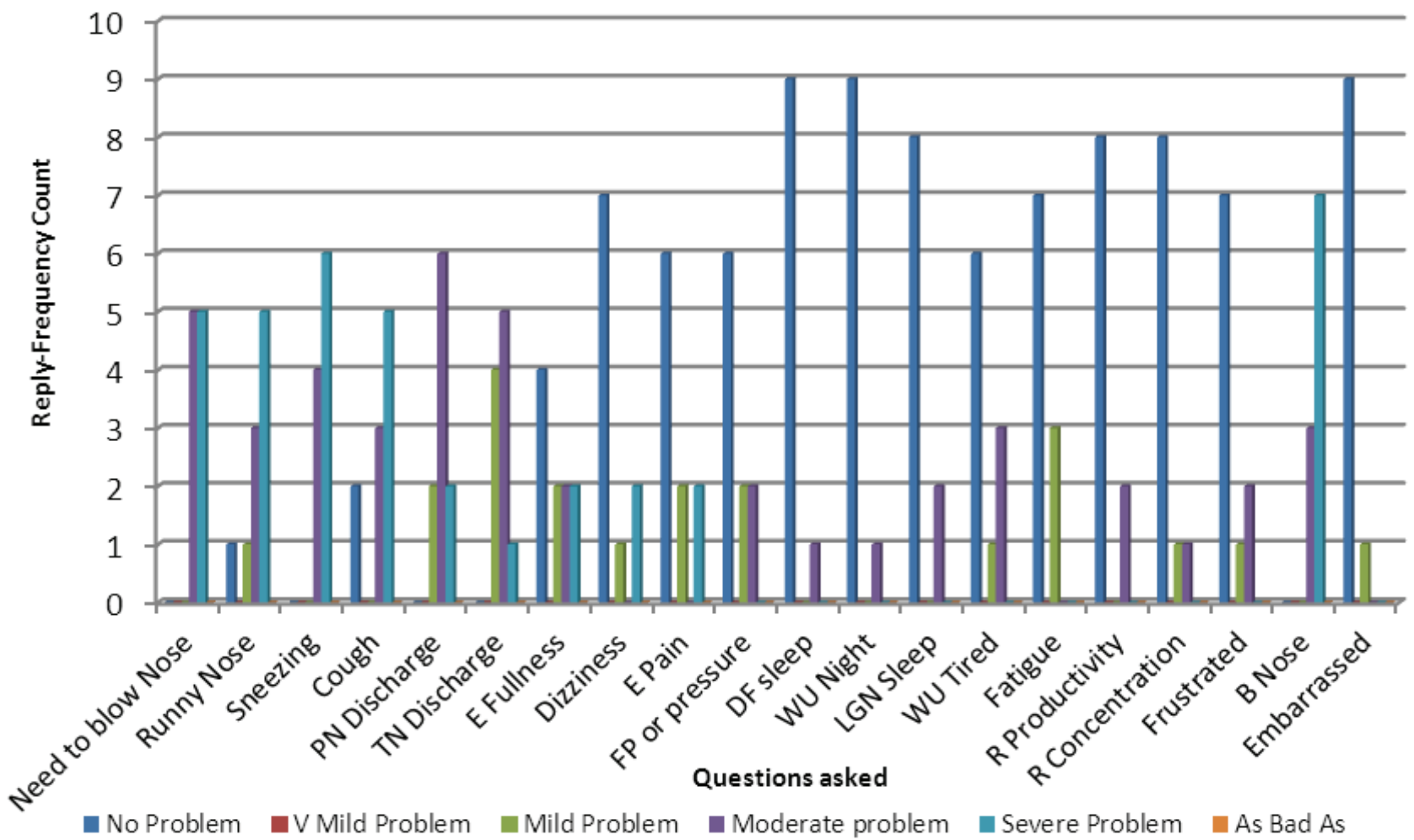

Figure 2. Graphical representation of disease group $(n=10)$. This figure highlights the higher prevalence of symptoms and the greater variation in symptoms, ranging from "mild" to "severe" symptom scores, within the disease group. Abbreviations: PN Discharge = Post Nasal discharge, TN Discharge $=$ Thick Nasal, E Fullness $=$ Ear fullness, E Pain $=$ Ear Pain, FP or Pressure $=$ Facial Pain or Pressure, DF Sleep $=$ Difficulty Falling Asleep, WU Night $=$ Wake Up at Night, LGN Sleep $=$ Lack Good Night Sleep, WU Tired = Wake Up Tired, R Productivity = Reduced productivity, R Concentration = Reduced Concentration, B Nose = Blocked Nose. 'As bad As' $=$ The symptom is reported as being 'As Bad As It Can Be'

Table 1. Reliability statistic: Cronbach's alpha value for pilot project data.

\begin{tabular}{|ccc|}
\hline $\begin{array}{c}\text { Data group from } \\
\text { Pilot Project }\end{array}$ & $\begin{array}{c}\text { Cronbach's alpha } \\
\text { value }\end{array}$ & N of Items \\
\hline Disease subgroup & .906 & 20 \\
\hline Healthy subgroup & .214 & 20 \\
\hline All pilot project data & .952 & 20 \\
\hline
\end{tabular}

The reliability test of the MSYPQ was carried out using Cronbach's alpha, a measure of internal consistency or reliability. There is a consensus that an alpha value of greater than 0.7 shows good reliability within an instrument. The ' $\mathrm{N}$ of Items' represents the twenty questions that were responded to by each of the ten individuals in the healthy or disease group.

with disease. Responses in the healthy were very mild or mild for those few symptoms which did exist, with the exception of one individual with moderate nasal blockage. No healthy subject had severe or as bad as it can be symptoms.
The disease group showed significant internal variation with respect to symptoms (Figure 2). This is also represented in the standard deviation which is much greater for those with disease and shows the variability in severity of these symptoms.

\section{Reliability Analysis}

The reliability test of the MSYPQ was carried out using Cronbach's alpha, a measure of internal consistency or reliability. There is a consensus that an alpha value of greater than 0.7 shows good reliability within an instrument ${ }^{(35)}$. The Cronbach's alpha value was calculated for both disease and healthy sub groups (Table 1).

The ' $\mathrm{N}$ of Items' represents the twenty questions that were responded to by each of the ten individuals in the healthy or disease group (Table 1). The results highlighted that the disease group has a very reliable and consistent scoring; however, the lower alpha value of the healthy sub group can be attributed to one of the considerations of this statistical test, which is that Cronbach's alpha is a reliability test which detects scoring on a unidirectional scale. The healthy group responses are on a multi- 
dimensional scale which means that the alpha scoring may need further analysis. However, this analysis goes beyond the scope of this paper and, importantly, we need to detect the reliability of the entire questionnaire. All the data collected from the pilot project from the twenty healthy and disease subjects was analysed, without subgroup division, and the alpha was calculated as 0.952 (Table 1). This significantly high value shows that there is good internal consistency within the questionnaire and verifies the MSYPQ as being a disease specific and reliable tool.

\section{Discussion}

Although rhinosinusitis may not be a severe disease, in that it is not usually life threatening, this consideration under-reflects the impact of the disease on the individual. Rhinitis has been shown to significantly affect social well-being, school and learning performance as well as impacting on work productivity thus having a substantial impact on quality of life ${ }^{(9,10,13,38,39)}$. In addition, the financial costs incurred by those with rhinitis may be substantial. There has been little data obtained on rhinosinusitis which might be expected to have as much, if not, more impact upon quality of life, work and school performance.

The description of the quality of life is envisioned by critics to exist separately from the description of health status. Quality of life is a uniquely personal experience that reflects not only health status ${ }^{(27,28,40)}$ but also other factors and circumstances in a patient's life: only the individual patient can describe his/her quality of life. Schipper et al have defined HRQL (health related quality of life) as "the functional effects of an illness and its consequent therapy upon a patient, as perceived by the patient" (28-30).

The MSYPQ was derived from the MSNOT-20 disease specific and health related quality of life tool ${ }^{(24)}$, which itself was developed following one modification of SNOT-20 questionnaire in the disease specific section, plus the inclusion of section 1 (demographic details) and section 3 (quality of life and treatment).
This was developed with the aim of providing an evaluative instrument capable of assessing both disease and health status change over time.

The results of this small pilot project using MSYPQ shows that it correlates well with the EPOS criteria for rhinosinusitis.

There was a clear difference between the two groups in the symptom scores for each of the individual twenty questions. The severity comparison analysis confirms that disease (EPOS+) subjects have higher scores than healthy (EPOS-) indicating the differentiation between the diseased and non-diseased subjects. The total score mean and standard deviation was higher in disease compared to healthy subjects with very little overlap. The variability in severity of the disease symptoms in the assessed was also well documented by the MSYPQ. The symptom "blocked nose" was also present in a mild or moderate form in one or two of the healthy group, so, contrary to our expectations, it is not as good a discriminator as most of the other symptoms. Cronbach's alpha however confirms that the MSYPQ is a reliable instrument for assessing rhinosinusitis.

This study has verified the usefulness and validity of the MSYPQ to differentiate school children with rhinitis/rhinosinusitis from their healthy peers and enabled its use in a larger survey.

\section{Acknowledgement}

The authors would like to acknowledge all the secondary school students who took part and the teachers involved; without their co-operation this would not have been possible.

\section{Authorship contribution}

This work forms part of a submission for an MSc in Allergy. Dr Amtul Salam Sami is the researcher and author, Dr Glenis K Scadding is the research supervisor and co-author.

\section{Conflicts of Interest}

No conflict of interest exists.

\section{References}

1. Lanza DC, Kennedy DW. Adult rhinosinusitis defined. Otolaryngol Head Neck Surg. 1997; 117(3 Pt 2): S1-S7.

2. Fokkens W, Lund V, Mullol J. European position paper on rhinosinusitis and nasal polyps 2007. Rhinol Suppl. 2007; (20): 1-136.

3. Ghouri N, Hippisley-Cox J, Newton J, Sheikh A. Trends in the epidemiology and prescribing of medication for allergic rhinitis in England. J R Soc Med. 2008; 101: 466-472.

4. Moser FG, Panush D, Rubin JS, Honigsberg RM, Sprayregen S, Eisig SB. Incidental paranasal sinus abnormalities on MRI of the brain. Clin Radiol. 1991; 43: 252-254.

5. Leo $G$, Incorvaia $C$. The clinical spec- trum of rhinosinusitis in children. Int J Immunopathol Pharmacol. 2010; 231 Suppl): 24-28.

6. Mattucci KF, Greenfield BJ. Middle ear effusion--allergy relationships. Ear Nose Throat J. 1995; 74: 752-758.

7. Hellings PW, Fokkens WJ. Allergic rhinitis and its impact on otorhinolaryngology. Allergy. 2006; 61: 656-664.

8. Ray NF, Baraniuk JN, Thamer M, Rinehart CS, Gergen PJ, Kaliner M, et al. Healthcare expenditures for sinusitis in 1996: contributions of asthma, rhinitis, and other airway disorders. J Allergy Clin Immunol. 1999; 103: 408-414.

9. Vuurman EF, van Veggel LM, Uiterwijk MM, Leutner D, O'Hanlon JF. Seasonal allergic rhi- nitis and antihistamine effects on children's learning. Ann Allergy. 1993; 71: 121-126.

10. Simons FE. Learning impairment and allergic rhinitis. Allergy Asthma Proc. 1996; 17: 185-189.

11. Cockburn IM, Bailit HL, Berndt ER, Finkelstein SN. Loss of work productivity due to illness and medical treatment. J Occup Environ Med. 1999; 41: 948-953.

12. Asher MI, Montefort S, Bjorksten B, et al. Worldwide time trends in the prevalence of symptoms of asthma, allergic rhinoconjunctivitis, and eczema in childhood: ISAAC Phases One and Three repeat multicountry cross-sectional surveys. Lancet. 2006 26; 368: 733-743. 
13. Hattevig G, Kjellman B, Bjorksten B. Appearance of IgE antibodies to ingested and inhaled allergens during the first 12 years of life in atopic and non-atopic children. Pediatr Allergy Immunol. 1993; 4: 182186.

14. Vuurman $E F$, van Veggel $L M$, Sanders $R L$, Muntjewerff ND, O'Hanlon JF. Effects of semprex-D and diphenhydramine on learning in young adults with seasonal allergic rhinitis. Ann Allergy Asthma Immunol. 1996; 76: 247252.

15. Braun-Fahrlander C, Wuthrich B, Gassner M, et al. Validation of a rhinitis symptom questionnaire (ISAAC core questions) in a population of Swiss school children visiting the school health services. SCARPOL-team. Swiss Study on Childhood Allergy and Respiratory Symptom with respect to Air Pollution and Climate. International Study of Asthma and Allergies in Childhood. Pediatr Allergy Immunol. 1997; 8: 75-82

16. Duhme H, Weiland SK, Rudolph P, Wienke A, Kramer A, Keil U. Asthma and allergies among children in West and East Germany: a comparison between Munster and Greifswald using the ISAAC phase I protocol. International Study of Asthma and Allergies in Childhood. Eur Respir J. 1998; 11: 840-847.

17. Frosh AC, Sandhu G, Joyce R, Strachan DP. Prevalence of rhinitis, pillow type and past and present ownership of furred pets. Clin Exp Allergy. 1999; 29: 457-460.

18. Hesselmar B, Aberg N, Aberg B, Eriksson B, Bjorksten B. Does early exposure to cat or dog protect against later allergy development? Clin Exp Allergy. 1999; 29: 611-617.

19. Shaheen SO, Aaby P, Hall AJ, Barker DJ, Heyes CB, Shiell AW, et al. Measles and atopy in Guinea-Bissau. Lancet. 1996; 347(9018): 1792-1796.

20. Yemaneberhan $H$, Bekele $Z$, Venn A, Lewis $S$, Parry E, Britton J. Prevalence of wheeze and asthma and relation to atopy in urban and rural Ethiopia. Lancet. 1997; 350(9071): 85-90.

21. Odhiambo JA, Ng'ang'a LW, Mungai MW Gicheha CM, Nyamwaya JK, Karimi F, et al. Urban-rural differences in questionnairederived markers of asthma in Kenyan school children. Eur Respir J. 1998; 12: 1105-1112.

22. Samet JM, Speizer FE. Assessment of health effects in epidemiologic studies of air pollution. Environ Health Perspect. 1993; 101 Suppl 4: 149-154.

23. Calderon-Garciduenas L, Osorno-Velazquez A, Bravo-Alvarez H, Delgado-Chavez R, Barrios-Marquez R. Histopathologic changes of the nasal mucosa in southwest Metropolitan Mexico City inhabitants. Am J Pathol. 1992; 140: 225-232.

24. Sami A. Epidemiology of Rhinitis in secondary school children using MSYPQ and comparison with Modified SNOT-20 used in adult community based survey. 2010 Nov 4; European Academy of Allergy and Clinical Immunology; 2010 p. 25.

25. Kirshner B, Guyatt G. A methodologica framework for assessing health indices. $J$ Chronic Dis. 1985; 38: 27-36.

26. Piccirillo JF, Edward D, Haiduck A Psychometric and clinimetric validity of the 31 items Rhinosinusitis outcome measure (RSOM-31). Am J Rhinol. 1995; 9: 297-306

27. Guyatt GH, Bombardier C, Tugwell PX Measuring disease-specific quality of life in clinical trials. CMAJ. 1986; 134: 889-895.

28. Guyatt GH, Cook DJ. Health status, quality of life, and the individual. JAMA. 1994; 24; 272: 630-631.

29. Torrance GW. Utility approach to measuring health-related quality of life. J Chronic Dis 1987; 40: 593-603.

30. Tugwell P, Bombardier C, Buchanan WW Goldsmith $\mathrm{CH}$, Grace E, Hanna B. The MACTAR Patient Preference Disability Questionnaire--an individualized functional priority approach for assessing improvement in physical disability in clinical trials in rheumatoid arthritis. J Rheumatol. 1987; 14: 446-451.

31. Gill TM, Feinstein AR. A critical appraisal of the quality of quality-of-life measurements. JAMA. 1994; 272: 619-626.

32. Piccirillo JF, Merritt MG, Jr., Richards ML. Psychometric and clinimetric validity of the 20-Item Sino-Nasal Outcome Test (SNOT20). Otolaryngol Head Neck Surg. 2002; 126: 41-47.
33. Jessen M, Malm L. Definition, prevalence and development of nasal obstruction. Allergy. 1997; 52 (40 Suppl): 3-6.

34. Fokkens W, Lund V, Bachert $C$, et al. EAACl position paper on rhinosinusitis and nasal polyps executive summary. Allergy. 2005; 60: 583-601.

35. Nunnaly JC. Psychometric theory. 2nd ed. New York: McGraw-Hill; 1978.

36. Bertelsen RJ, Carlsen KC, Carlsen KH. Rhinitis in children: co-morbidities and phenotypes. Pediatr Allergy Immunol. 2010; 21: 612-622.

37. Lundback B. Epidemiology of rhinitis and asthma. Clin Exp Allergy. 1998; 28 Suppl 2: 3-10.

38. Craig TJ, Teets S, Lehman EB, Chinchilli VM, Zwillich C. Nasal congestion secondary to allergic rhinitis as a cause of sleep disturbance and daytime fatigue and the response to topical nasal corticosteroids. J Allergy Clin Immunol. 1998; 101: 633-637.

39. Aberg N, Hesselmar B, Aberg B, Eriksson B. Increase of asthma, allergic rhinitis and eczema in Swedish schoolchildren between 1979 and 1991. Clin Exp Allergy. 1995; 25: 815-819.

40. Juniper EF, Guyatt GH. Development and testing of a new measure of health status for clinical trials in rhinoconjunctivitis. Clin Exp Allergy. 1991; 21: 77-83.

Dr Amtul Salam Sami

1 Cow Leaze

Beckton

London, E6 6WX

United Kingdom

Tel: +44-20-7474 2595

Fax: +44-20-7474 7878

Email: amtul_salam@hotmail.com 


\section{APPENDIX}

Modified SNOT-20 for Young Person

\section{RHINITIS QUESTIONNAIRE}

SECTION 1

Modified Sinonasal Out Come Test - 20 for Young Person

Young Person ID No.

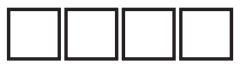

Date

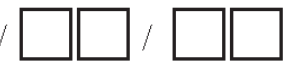

Name of School

Address

Post Code
1. Gender
Male
Female
$\square 1$
$\square 2$

2. What is your ethnic background?

$\begin{array}{llllll}\text { White } & \square 1 & \text { Chinese } & \square 4 & \text { Bangladeshi } & \square 7 \\ \text { Black Caribbean } & \square 2 & \text { Pakistani } & \square 5 & \text { Others } & \square 8 \\ \text { Black African } & \square 3 & \text { Indian } & \square 6 & \text { Please Specify } & \square\end{array}$

3. Parents/Guardians

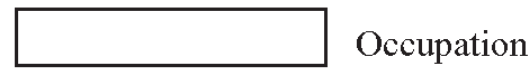

4. Please tick the box which best describes the type of accommodation in which you live

Whole house $\square 1 \quad$ Bungalow $\square 2 \quad$ Purpose built flat $\square 3$

Shared House $\square 4$

5. Is there in your immediate family (parents/children/brother/sister) Yes No

Or blood relatives a history of Asthma?

$\square_{1} \square_{2}$

6. Is there in your immediate family (parents/children/brother/sister) Yes No Or blood relatives a history of Eczema?

7. Is there in your immediate family (parents/children/brother/sister) Yes No Or blood relatives a history of Hay Fever?

8. Is there in your immediate family (parents/children/brother/sister) Yes No Or blood relatives a history of Food Allergy? 
Young Person ID No.

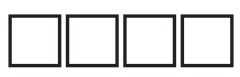

SECTION 2

Below you will find a list of symptoms and social/emotional consequences of Rhinosinusitis we would like to know more about these problems and would appreciate your answering the following question to the best of your ability. There are no right or wrong answers, and only you can provide us with this information. Please rate your problems as they have been over the past two weeks. Thank you for your participation. Do not hesitate to ask for assistance if necessary.

a. Considering how server the problem is when you experienced it and how frequently it happens please rate each item below on how "bad" it is by a tick in the box that correspond with how you feel using the scale.

\begin{tabular}{|lll|}
\hline $0=$ no problem & $1=$ very mild problem & $2=$ mild or slight problem \\
3 moderate problem & $4=$ severe problem & $5=$ as bad as it can be \\
\hline
\end{tabular}

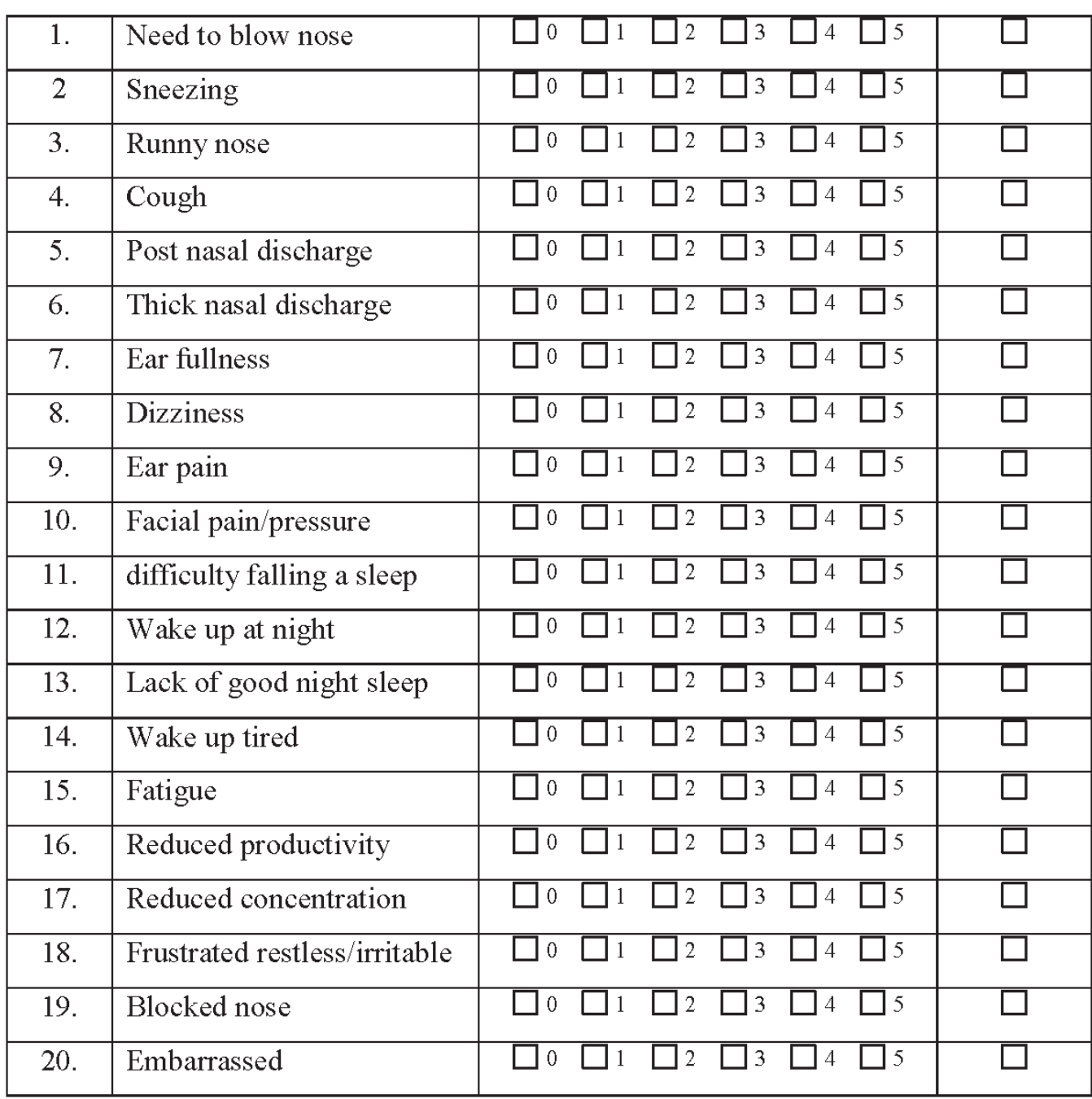

b. Please tick the most important affecting your health (maximum of 5 items)

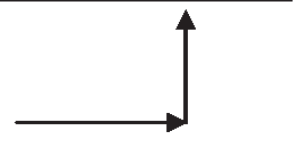


Young Person ID No.

SECTION 3

To be filled in only if you marked any of the boxes on the SNOT-20 with score 1, 2 , 3,4 or 5 .

1. Do your nasal symptoms occur for?

(a) Less than 4 days per week or Less than 4 weeks at a time $\quad$ Yes $\square 1 \quad$ No $\square 2$

(b) More than 4 days per week or More than 4 weeks at a time Yes $\square 1 \quad$ No $\square 2$

2. Do your nasal symptoms cause any of these?

Abnormal sleep

Impairment of daily activities, sport, leisure

Problems caused at school

Trouble some symptoms

Are they intermittent

$\begin{array}{cc}\text { Yes } \square 1 & \text { No } \square 2 \\ \text { Yes } \square 1 & \text { No } \square 2 \\ \text { Yes } \square 1 & \text { No } \square 2 \\ \text { Yes } \square 1 & \text { No } \square 2 \\ \text { Yes } \square 1 & \text { No } \square 2\end{array}$

3. How long have you had these problems?

Less than 6 weeks

$\square 1$ 1 to 5 Years $\square 3$

More than 6 weeks but less than 1 year $\square 2$ More than 5 years $\square 4$

4. Do you ever get treatment for these problems? Yes $\square 1 \quad$ No $\square 2$

5. Where do you usually get the treatment for the problem?

G.P. $\square 1$
Chemist 2
Alternative therapist

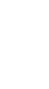


Young Person ID No.

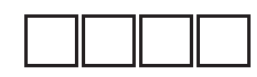

SECTION 3 cont...

8. What treatment do you usually get?

9. Does the treatment in any way?

Yes $\square 1 \quad$ No $\square 2$

10. How often do you have to use treatment for these problems?

Most days $\square 1 \quad$ once or twice per day $\square 3$

Once or twice per week $\square 2 \quad$ once or twice per year $\quad \square 4$

11. How much do you think you spend on treatment for your problem?

Less than $£ 5$ per month $\square 1 \quad$ More than $£ 20$ per month
More than $£ 5$ but less than $£ 20$ per month $\square 2 \quad$ Others
Please specify $£ \quad \square \square \square . \square \square$

12. Have you ever seen an ear nose throat specialist for $\quad$ Yes $\square 1 \quad$ No $\square 2$ your Problem in past year?

13. Have you ever had an operation

Yes $\square 1 \quad$ No $\square 2$

14. Do you ever have to take time off from school Yes $\square 1 \quad$ No $\square 2$ because of your nose/sinus problem?

15. How many days in past year have you taken time

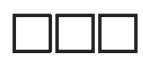
off from school because of your nose/sinus problem? 